\title{
Modulation by Bovine Serum Albumin of Stimulated Formation of Cyclic AMP in Guinea Pig Hippocampus
}

\author{
Akemichi BABA, Yoshihiro KUMAGAE, Tohru TATSUNO \\ and Heitaroh IWATA \\ Department of Pharmacology, Faculty of Pharmaceutical Sciences, \\ Osaka University, 1-6 Yamada-oka, Suita, Osaka 565, Japan \\ Accepted July 25, 1984
}

\begin{abstract}
Excitatory amino acids such as glutamate. aspartate and cysteine sulfinic acid (CSA) markedly stimulate formation of cyclic AMP in incubated brain slices (1), and of these acidic amino acids, CSA had the greatest effect (2, 3). The mechanisms by which these excitatory amino acids enhance the formation of cyclic AMP have been studied by several workers, and the results suggest that their effects may be due to common
\end{abstract} mechanisms; e.g., possible common receptors or release of adenosine (1, 2, 4). However. in the previous studies using various agonists and antagonists of excitatory amino acids, we indicated that excitatory amino acids stimulated cyclic AMP formation through different mechanisms $(3,5)$. With respect to the characteristics of the stimulatory effect of these amino acids on cyclic AMP formation in brain slices, two points should be mentioned. First, very high concentrations, usually millimolar orders, are required. Second, excitatory amino acids fail to stimulate adenylate cyclase in cell-free systems. Thus, it is not clear that excitatory amino acids actually stimulate adenylate cyclase through their own receptors in a similar manner to the case of catecholamines.

Bovine serum albumin (BSA) has been utilized as an effective means of removing fatty acids and lysophosphatides from membranes because BSA is known to have a high capacity for binding these substances (6). BSA washing of the brain preparations has resulted in modulations of membrane functions; e.g., receptor functions (6), amino acid transports (7) and phospholipid metabolism (8). Thus, BSA seems to be an effective means for the characterization of signal transduction across the membranes.
For a further characterization of excitatory amino acids-induced cyclic AMP formation, we examined the effects of BSA on the cyclic AMP response to excitatory amino acids, adenosine and histamine in slices of guinea pig hippocampus, which is the most susceptible region to the stimulatory effect of excitatory amino acids on cyclic AMP formation (3).

The slices of hippocampal formation of male guinea pigs were prepared as described previously (9). Preincubation and incubation of the slices were performed in Krebs-Ringer bicarbonate buffer (KR) as described elsewhere (3). In brief, after $60 \mathrm{~min}$ of preincubation, slices were incubated for $5 \mathrm{~min}$ at $37^{\circ} \mathrm{C}$ in the presence and absence of the agonists. Defatted BSA (Sigma) was added $5 \mathrm{~min}$ before the addition of the stimulants. Histamine-sensitive adenylate cyclase was assayed using hippocampal homogenates as an enzyme source according to the methods of Harada et al. (10). Cyclic AMP concentrations were determined as described elsewhere (3).

Figure 1 depicts the effects of BSA ( 5 $\mathrm{mg} / \mathrm{ml}$ ) on the facilitation of cyclic AMP formation by the various agents. Stimulations of cyclic AMP formation by maximal doses of adenosine (Ade) and histamine (Hist) were reduced to about 40 to $50 \%$ by $B S A$. It is noteworthy that BSA attenuated the effect of CSA but not of glutamate (Glu). However, the inhibition of the CSA-effect was not as large as those of adenosine and histamine. The inhibitory effect of BSA on the action of histamine was observed from a dose of 2.5 $\mathrm{mg} / \mathrm{ml}$ (data not shown).

As shown in Fig. 2A, activity of histaminesensitive adenylate cyclase was observed in 
hippocampal homogenates, though maximal stimulation and the doses of histamine were slightly different from the previous study (10). BSA decreased the maximal response of histamine without affecting the basal and GTP-stimulated activities of adenylate cyclase. The dose-response curve of BSA is shown in Fig. 2B: it inhibited the effect of histamine by about $40 \%$ at the concentration of $1 \mathrm{mg} / \mathrm{ml}$. It was found that

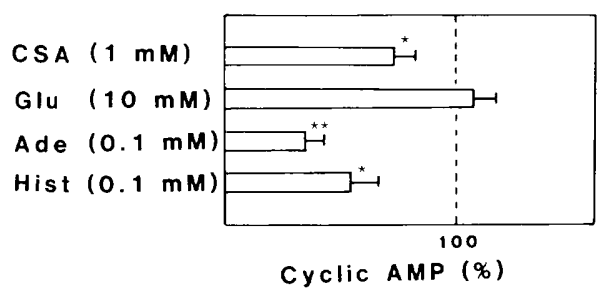

Fig. 1. Effect of BSA on cyclic AMP formation elicited by various agents in guinea pig hippocampal slices. Values (means \pm S.E. from 9-15 experiments) are percentages of the corresponding BSA-free control. BSA-free control values (100\%) are as follows: cysteine sulfinic acid (CSA), 120 12.5 :

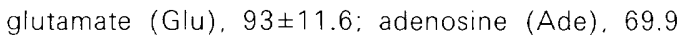
\pm 11.0 ; histamine (Hist), $81.5 \pm 10.1$ (pmol/mg protein $/ 5 \mathrm{~min})$. ${ }^{*} \mathrm{P}<0.05,{ }^{*} \mathrm{P}<0.01$. compared to the corresponding BSA-free control.

A.

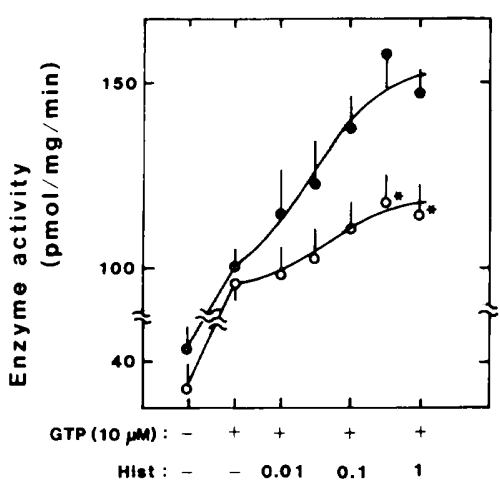

Hist concentration (mM) trypsin inhibitor and ribonuclease, which have no ability to bind free fatty acids, did not inhibit the enzyme activity at the concentration of $5 \mathrm{mg} / \mathrm{ml}$, whereas $\beta$-lactoglobulin, which has the ability to bind free fatty acids as well as BSA, inhibited the response to histamine by $30 \%$ at the concentration of 1 $\mathrm{mg} / \mathrm{ml}$ (data not shown). In addition, free unsaturated fatty acids were increased in the hippocampal membrane pellets during $10 \mathrm{~min}$ of incubation, and the increases were prevented by a simultaneous addition of BSA; the content of unsaturated fatty acids $(\mu \mathrm{g} / \mathrm{mg}$ protein) were as follows: 0-time, 1.88; control, 2.49; BSA $5 \mathrm{mg} / \mathrm{ml}, 1.36$. It is reasonable that free unsaturated fatty acids are increased during incubation because nerve membranes have various types of phospholipase $A_{2}$ activities (11). Thus, the present results indicate that the inhibitory effect of BSA on the histamine-induced stimulation of adenylate cyclase is related to its ability to bind free fatty acids. Decrease in free unsaturated fatty acids in the membranes by BSA may result in decrease of membrane fluidity because incorporation of polyunsaturated fatty acids into the membranes is accompanied by increase of membrane fluidity (12). Rate of adenylate cyclase

B.

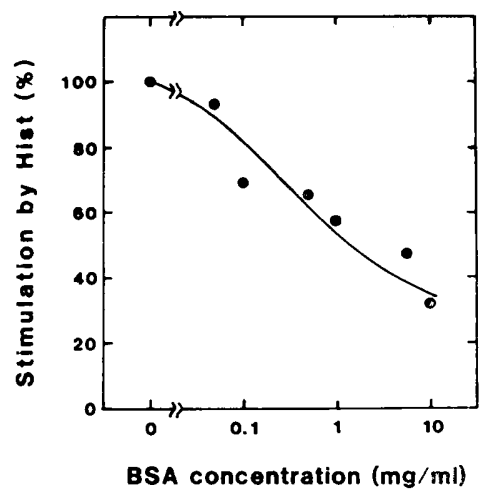

Fig. 2. Effect of BSA on histamine-sensitive adenylate cyclase activity of hippocampal homogenates. A. Dose-response curve of histamine. Adenylate cyclase activity of hippocampal homogenates was examined in the presence ( $)$ and absence of $5 \mathrm{mg} / \mathrm{ml}$ BSA (O) according to the method described by Harada et al. (10). Values are the means $\pm S$.E. of $6-8$ experiments. $P<0.05$, compared to the corresponding control (absence of BSA). B. Dose-response curve of BSA. Results were expressed as percentages of the control. 
activation by the receptors is dependent on membrane fluidity (13). In the previous study, we also suggested that linoleic acid can accelerate functional coupling of the receptors and adenylate cyclase in cerebral cortical slices (14). It is possible that the attenuation of the histamine-responsiveness by BSA is related to changes in membrane fluidity of the preparations.

BSA reduced the stimulatory effect of CSA on cyclic AMP formation but not that of glutamate (Fig. 1). On the basis of the argument described above, the result suggests a possible involvement of the lipid environment in the stimulatory effect of CSA but not in that of glutamate. The present results, as those of the previous studies $(3,5,11)$, also negate the hypothesis of excitatory amino acids stimulating cyclic AMP formation by common mechanisms.

Acknowledgments: This research was supported by grants from the Ministry of Education. Science and Culture and the Ministry of Health and Welfare of Japan in 1983.

\section{References}

1 Shimizu, H., Ichishita, $H$. and Odagiri, $H_{\text {.: }}$ Stimulated formation of cyclic adenosine $3^{\circ} .5^{\circ}$ monophosphate by aspartate and glutamate in cerebral cortical slices of guinea pig. J. Biol. Chem. 249, 5955-5962 (1974)

2 Shimizu, H., Ichishita, H., Tateishi, M. and Umeda, I.: Characteristics of the amirio acid receptor site mediating formation of cyclic adenosine $3^{\prime}, 5^{\prime}$-monophosphate in mammalian brains. Mol. Pharmacol. 11, 223-231 (1975)

3 Baba, A., Lee, E., Tatsuno, T. and Iwata, H.: Cysteine sulfinic acid in the central nervous system: Antagonistic effect of taurine on cysteine sulfinic acid-stimulated formation of cyclic AMP in guinea pig hippocampal slices. J. Neurochem. 38, 1280-1285 (1982)

4 Bruns, R.F., Pons, F. and Daly, J.W.: Glutamateand veratridine-elicited accumulations of cyclic AMP in brain slices: A role for factors which potentiate adenosine-responsive systems. Brain Res. 189, 550-555 (1980)

5 Baba, A., Tatsuno, T., Kumagae, Y. and Iwata, H.: Irihibitory effect of taurine on the formation of cyclic AMP in guinea pig hippocampus. In Sulfur Amino Acids: Biochemical and Clinical Aspects, Edited by Kuriyama, K. Huxtable, R.J. and Iwata, H., p. 161-168. Alan R. Liss, Inc.. New York (1983)

6 Azhar, S., Hajra, A.K. and Menon, K.M.J.: Gonadotropin receptors in plasma membranes of bovine corpus luteum. II. Role of membrane phospholipids. J. Biol. Chem. 251, 7405-7412 (1976)

7 Rhoads, D.E., Kaplan, M.A.. Peterson, N.A. and Raghupathy, E.: Effects of free fatty acids on synaptosomal amino acid uptake systems. J. Neurochem. 38, 1255-1260 (1982)

8 Strosznajder, J., Foudin, L., Tang, W. and Sun, G.Y.: Serum albumin washing specifically enhances arachidonate incorporation into syriaptosomal phosphatidylinositols. J. Neurochem. 40, 84-90 (1983)

9 Baba, A., Okumura, S., Mizuo $H$. and Iwata, $H$ : Inhibition by diazepam and $\gamma$-aminobutyric acid of depolarization-iriduced release of $\left[{ }^{14} \mathrm{C}\right]$ cysteine sulfinate and $\left[{ }^{3} \mathrm{H}\right]$ glutamate in rat hippocampal slices. J. Neurochem. 40, 280-284 (1983)

10 Harada, M., Terai, M. and Maeno, H.: Effect of a new potent $\mathrm{H}_{2}$-receptor antagonist 3[[[2[(diaminomethylene) amino]-4-thiazolyl] methyl] thio]- $\mathrm{N}^{2}$-sulfamoylpropionamidine (YM-11170) on gastric mucosal histaminesensitive adenylate cyclase from guinea pig. Biochem. Pharmacol. 32, 1635-1640 (1983)

11 Gullis, R.J. and Rowe, C.E.: The stimulation by transmitter substances and putative transmitter substances of the net activity of phospholipase $A_{2}$ of synaptic membranes of cortex of guineapig brain. Biochem. J. 148, 197-208 (1975)

12 Karnovsky, M.J., Kleinfeld, A.M., Hoover, R.L. and Klausner, R.D.: The concept of lipid domains in membranes. J. Cel! Biol. 94, 1-6 (1982)

13 Rimon, G., Hanski, E., Braun, S. and Levitzki, A.: Mode of coupling between hormone receptors and adenylate cyclase elucidated by modulation of membrane fluidity. Nature 276, 394-396 (1978)

14 Baba, A., Tatsuno, T. and Iwata, H.: Modulation by unsaturated fatty acids of norepinephrineand adenosine-induced formation of cyclic AMP in brain slices. J. Neurochem 42, 192-197 (1984) 